\title{
Bilateral well differentiated paratesticular liposarcoma: A rare case report
}

\author{
Funda Bozkurt ${ }^{1}$, Hamide Sayar ${ }^{2}$, Tuba Kara ${ }^{2 *}$ and Mehmet Ozgur OT ${ }^{3}$ \\ ${ }^{1}$ Assistant Doctor, Department of Pathology, Mersin University School of Medicine, Mersin, Turkey \\ ${ }^{2}$ Assistant Professor doctor, Department of Pathology, Mersin University School of Medicine, Mersin, Turkey \\ ${ }^{3}$ Assistant Professor doctor, Department of General Surgery, Mersin University School of Medicine, Mersin, Turkey
}

\begin{abstract}
Introduction: Liposarcomas are soft tissue sarcomas originating from adipose tissue. They usually appear in the deep soft tissues of the extremities and in the retroperitoneum. Paratesticular liposarcoma is extremely rare and has been reported as isolated cases.

Case: A 54-year-old male patient presented with a mass in both scrotum. He had previous history of inguinal hernia operation and was re-operated for a suspected relapse. Right and left paratesticular masses were removed. Histopathological examination of both masses revealed a tumor in lipoma-like morphology containing mature adipocytes separated by thin fibrous bands. Atypical spindle cells with hyperchromatic nuclei and lipoblasts with multivacuolized cytoplasm and large hyperchromatic nuclei were seen and a well-differentiated liposarcoma was diagnosed.

Conclusion: Paratesticular liposarcomas are rare tumors and there are few cases in the literature. The presence of well-differentiated liposarcoma should be investigated in patients with paratesticular masses clinically consistent with lipomas or inguinal hernia.
\end{abstract}

\section{Introduction}

Liposarcomas are soft tissue sarcomas originating from the adipose tissue [1]. It is usually seen in the deep soft tissues of the extremities and retroperitoneum. Liposarcoma is the most common soft tissue sarcoma that constitutes $30 \%$ of all mesenchymal tumors [2]. Sarcomas are very rare in the paratesticular region in general [3]. Paratesticular liposarcomas may arise from structures around the testis, including the distal tip of the spermatic cord [1]. They usually appear as painless, slow-growing masses diagnosed as lipomas or inguinal hernia [4]. Bilateral localized paratesticular liposarcoma is a rare entity. While there are less than 200 cases of paratesticular liposarcoma reported in the literature, only two cases we detected from these cases were bilateral localized $[5,6]$. The aim of this study was to present a rare case of bilateral paratesticular liposacoma and to contribute to the literature.

\section{Case report}

A 54-year-old male patient who was operated at another medical center 1.5 years ago because of inguinal hernia, admitted to our center because of swelling in both scrotum.

Ultrasonography revealed areas of fat tissue echogenicity that filled the entire scrotum, and both testes were found to be pushed by defined fat tissue echogenicity while testicular size and parenchymal echogenicity were found to be normal. The patient was operated for a suspected diagnosis of inguinal hernia and found to have bilateral mass with lobulated contours, which was thought to be compatible with lipoma and subsequently excised. On the macroscopic examination, the rightcoded material weighed $510 \mathrm{~g}$, was $17 \times 14.5 \times 9 \mathrm{~cm}$ in size, and the outer face was smooth with lobulated pattern. In addition, irregular tissue fragments of a total of $7 \times 5 \times 2 \mathrm{~cm}$ in size, rich in mature fat, were seen in the same container (Figure 1). The left-coded material was observed as yellow colored irregular pieces of tissue weighing $536 \mathrm{~g}$ and measuring $19.5 \times 17 \times 8 \mathrm{~cm}$ in size. The cross-sectional areas of the materials were mostly in matt appearance, yellow colored, medium hardness, rich in mature fatty tissue and contained focal calcified areas. There was no hemorrhage and necrosis (Figure 2). Histopathological examination revealed similar features in left and right coded materials. Lipoblasts with large hyperchromatic nucleus and multivaculized cytoplasm were detected. Atypical spindle cells with hyperchromatic nucleus were more prominently observed in thin fibrous bands that separated mature adipocytes into groups (Figure 3-5). In immunohistochemical study, focal areas were stained with S100. With these findings, the mass was diagnosed as well-differentiated liposarcoma with bilateral paratesticular location.

\section{Discussion}

Paratesticular region is a complex anatomical region consisting of epithelial, mesothelial and mesenchymal components histologically. Therefore, neoplasms developing in this region constitute heterogeneous tumor group showing different behavioral patterns. It is sometimes not possible to determine the exact origin of paratesticular tumors. Liposarcomas of this region may develop from adipose tissue

*Correspondence to: Tuba Kara, Department of Pathology, Mersin University School of Medicine, Mersin, Turkey, E-mail: karabacaktuba@hotmail.com

Key words: liposarcoma, paratesticular mass, bilateral

Received: December 06, 2018; Accepted: December 15, 2018; Published: December 17, 2018 


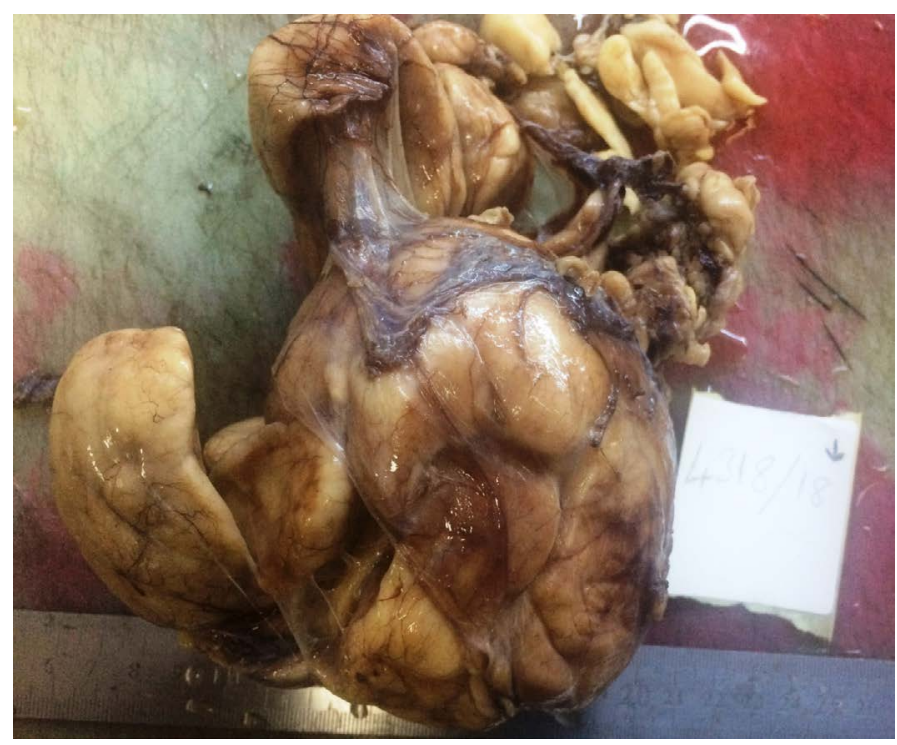

Figure 1. The gross appearance of right paratesticular mass

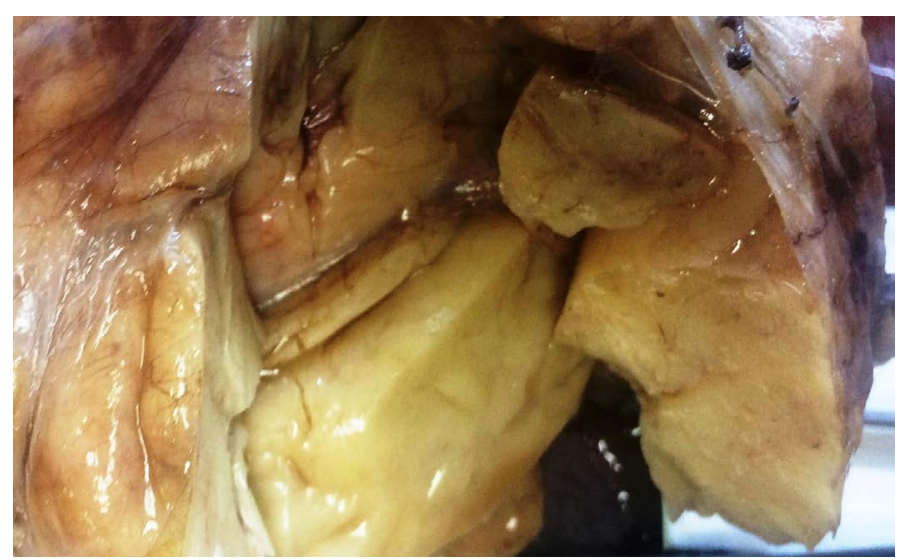

Figure 2. A cut surface having matt appearance, yellow colored, medium hardness, rich in mature fatty tissue

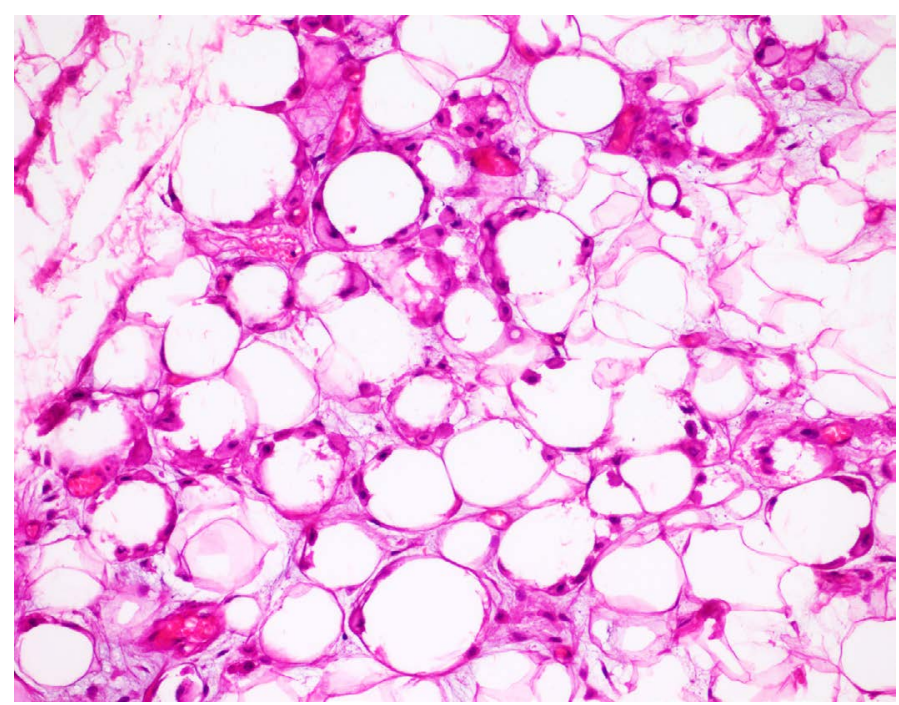

Figure 3. Lipoblasts with large hyperchromatic nucleus, multivacuolized cytoplasm and irregular shapes (HE x200)

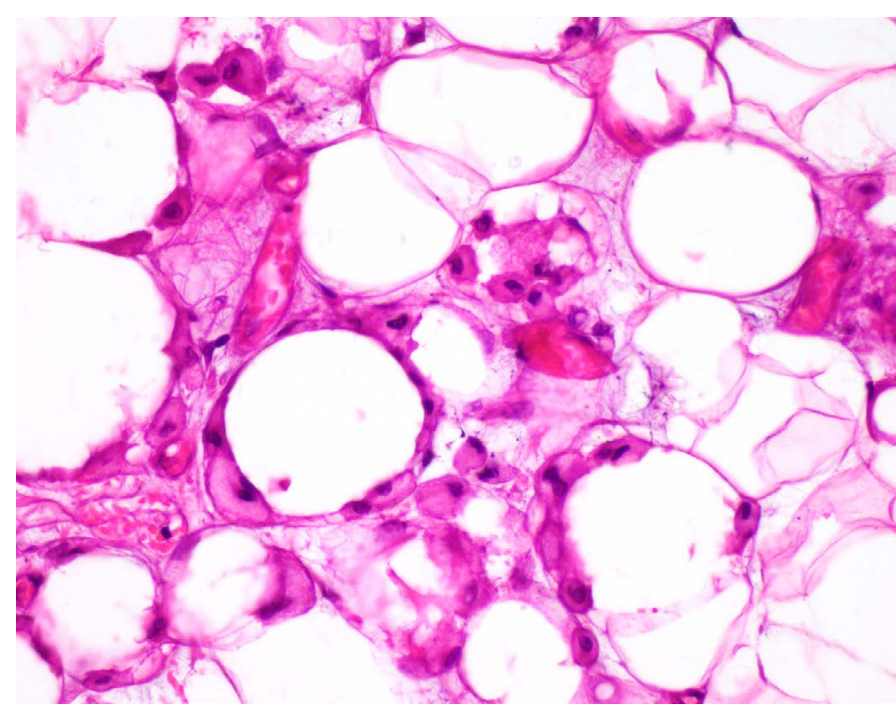

Figure 4. Lipoblasts with large hyperchromatic nucleus, multivacuolized cytoplasm and irregular shapes (HE x400)

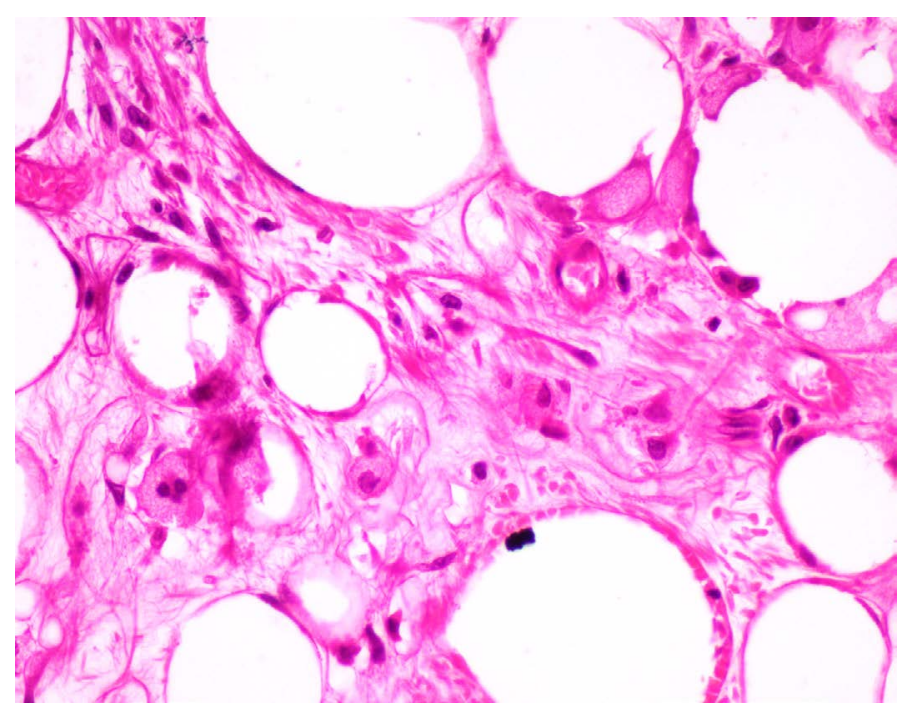

Figure 5. Atypical spindle cells with hyperchromatic nucleus (HE x400)

surrounding the spermatic cord or from malignant transformation of pre-existing lipoma [7]. Paratesticular liposarcomas constitute $12 \%$ of all liposarcomas [5].

In paratesticular tumors, most patients present with painless, slowly growing inguinal or scrotal mass [4]. They usually occur as unilateral masses and their size varies between 1.5 and $30 \mathrm{~cm}$ [8]. Although our case is similar to the cases mentioned in the literature by age, it is the third bilaterally located case of paratesticular liposarcoma that we detected in literature $[5,6]$.

Particularly well-differentiated paratesticular liposarcomas in ultrasonography are confused with lipoma or omentum in hernia sac due to homogenous fatty structure and these patients are usually diagnosed with inguinal hernia or lipoma before surgical intervention $[9,10]$. Magnetic resonance imaging can be used to assess the extent of the extension of the tumor, and to determine whether or not it is located in an extratesticular location. Computed tomography can help determine the morphological features and tumor localization [11]. 
According to the World Health Organization (WHO) 2013 classification of soft tissue tumors, there are four histological types of liposarcomas: well-differentiated, myxoid, pleomorphic and dedifferentiated. Well-differentiated liposarcomas are also subdivided into sclerosing liposarcoma, adipocytic liposarcoma and inflammatory liposarcoma [10]. Histological findings of two paratesticular liposarcomas bilaterally detected in the literature also show well differentiated features similar to our case $[5,6]$.

Well-differentiated liposarcomas are locally aggressive tumors and do not create metastasis potential unless they are dedifferentated [12]. The prognosis of paratesticular liposarcomas varies according to the histological type. The well-differentiated and myxoid type has a better prognosis, but the incidence of local recurrence is high in the incomplete resection [13]. In a study by Elizabeth et al., six of ten welldifferentiated paratesticular liposarcoma cases had recurrence after an average of 8 years [14].

Radical orchiectomy is the mainstay of initial treatment of paratesticular liposarcomas. The role of adjuvant radiotherapy or chemotherapy is still controversial. Radiotherapy can be used as an adjunct to surgical resection to prevent local recurrence [15].

\section{Conclusion}

Paratesticular liposarcomas are very rare tumors and there are very few cases that are detected bilaterally in the literature. In particular, ultrasonographic and clinical distinction of well-differentiated liposarcomas from lipoma and inguinal hernia may be difficult. Therefore, they may be diagnosed with lipoma or inguinal hernia in the preoperative period. Well-differentiated paratesticular liposarcoma should especially be considered in the differential diagnosis of inguinalscrotal lipoma like masses containing adipose tissue.

\section{References}

1. Bissada NK, Finkbeiner AE, Redman JF (1976) Paratesticular sarcomas: Review of management. J Urol 16: 198-200. [Crossref]
2. Montgomery E, Fisher C (2003) Paratesticular liposarcoma: A clinicopathological study. Am J Surg Pathol 27: 407 [Crossref]

3. John T, Portenier D, Auster B, Mehregan D, Drelichman A, et al. (2006) Leiomyosarcoma of scrotumcase report and review of literature. Urology 67: 424.e13424.e15.

4. Dreyfuss ML, Lybash S (1940) Malignant mixed tumor of the spermatic cord. J Urol 44: 314-324.

5. Raza M (2014) Bilateral paratesticular liposarcoma - a rare case report. J Surg Tech Case Rep 6: 15-17.

6. SopenaSutil R, Silan F, ButronVila MT, GuerreroRamos F, LagaronComba E et al (2016) Multidisciplinary approach to giant paratesticular liposarcoma. Can Urol Assoc $J$ 10: E316-E319. [Crossref]

7. Khoubehi B, Mishra V, Ali M, Motiwala H, Karim O (2002) Adult parat $\neg$ esticular tumours. BJU Int 90: 70715.

8. Rodríguez D, Barrisford GW, Sanchez A (2014) Primary spermatic cord tumours: Disease characteristics, prognostic factors, and treatment outcomes. Uro Oncol 32: 1925. [Crossref]

9. Coleman J, Brennan MF, Alektiar K (2003) Adult spermatic cord sarcomas: Management and results. Ann Surg Oncol 10: 66975. [Crossref]

10. Montgomery E, Fisher C (2003) Paratesticular liposarcoma: A clinicopathologic study. Am J Sur Pathol 27: 407. [Crossref]

11. Akbar SA, Sayyed TA, Jafri SZ, Hasteh F, Neill JS (2003) Multimodality imaging of paratesticular neoplasms and their rare mimics. Radiographics 23: 1461-1476. [Crossref]

12. Meşina C, Vasile I, Vîlcea ID, Vere CC, Georgescu CV, et al. (2010) Axillary and perianal leiomyosarcoma: report two cases. Rom J Morphol Embryol 51: 379-385. [Crossref]

13. Stranne J, Hugosson J, Lodding P (2006) Postradical retropubic prostatectomy inguinal hernia: An analysis of risk factors with special reference to preoperative inguinal hernia morbidity and pelvic lymph node dissection. J Urol 176: 20726. [Crossref]

14. Montgomery E, Fischer C (2003) Paratesticular liposarcoma: a clinicopathologic study. Am J Surg Pathol 27: 40.

15. Weiss SW, Rao VK (1992) Well-differentiated liposarcoma (atypical lipoma) of deep soft tissue of the extremities, retroperitoneum, and miscellaneous sites. Am J Surg Pathol 16: 10518. [Crossref]

Copyright: (C2018 Bozkurt F. This is an open-access article distributed under the terms of the Creative Commons Attribution License, which permits unrestricted use, distribution, and reproduction in any medium, provided the original author and source are credited. 